\title{
Energy-saving Type Rock Wool Making Process*
}

\section{Introduction}

Blast furnace slag is one of the principal raw materials for the production of rock wool. Conventionally, the cold blast furnace slag has been melted in cupola furnaces. However, this requires high melting energy. Nippon Steel Corp. and Nippon Steel Chemical Co., Ltd. have developed a new economical type of process that utilizes electric furnaces.

\section{Main Technologies and Fea- tures}

This process utilizes molten slag at high temperatures as received from the blast furnace. Main technologies are:

(1) Molten Slag Chargingthrough Mechanism

If oxygen is present in the electric furnace, the electrode life will be considerably shortened. For this reason, the method of molten slag charging in a steady $\mathrm{N}_{2}$ gas atmosphere was developed as shown in Fig. 1.

(2) Insulation of Electric Furnace

The refractory material must have excellent resistance to slag corrosion as well as good insulating properties. As a result of study, we have adopted a combination of refractories such as carbon block, $\mathrm{Al}_{2} \mathrm{O}_{3}-\mathrm{SiC}-\mathrm{C}$ series block, alumina insulating brick and ceramic fiber.

(3) Uniformity of Tapping Flow from Electric Furnace

For the fiberizing of slag, a constant tapping flow from the electric furnace is required. To achieve this, we have adopted a tilting-type electric furnace and tapping nozzle, which combines a water-cooled copper nozzle with a copper ring.

(4) Uniform Ghemical Composition and Uniform Temperature of Molten Slag

To obtain uniform fiberizing of molten slag, quartzite should be added at a ratio of about $10 \%$.

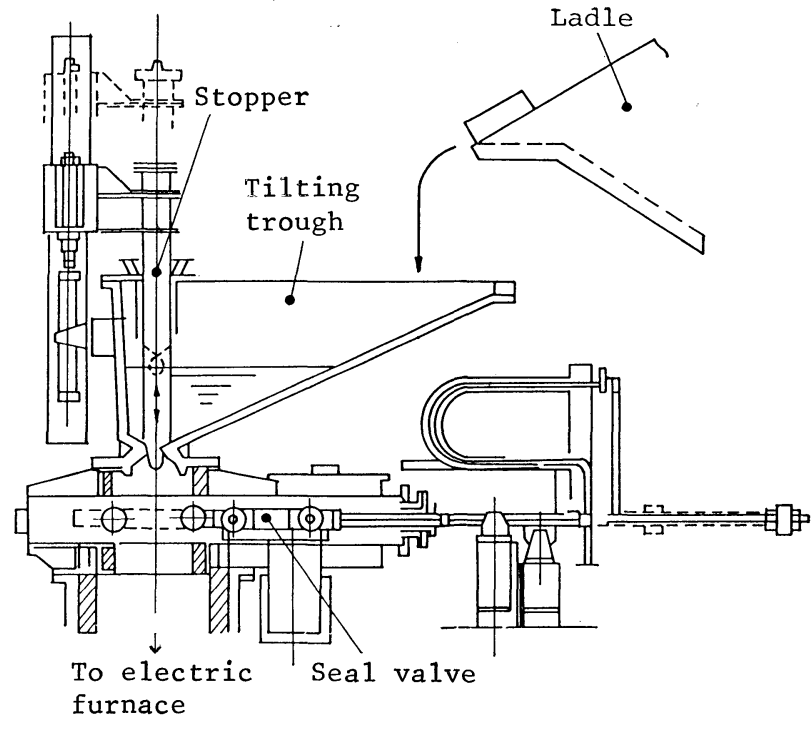

Fig. 1. Slag charging mechanism.
We charge the molten slag and quartzite simultaneously into the furnace. Further, after completion of the charging, $\mathrm{N}_{2}$ gas bubbling is performed for about $10 \mathrm{~min}$. The chemical composition of normal blast furnace slag and the required chemical composition of the molten slag are shown in Table 1.

\section{Results}

(1) The dissolving energy can be reduced by utilizing the sensible heat of molten slag $\left(400 \times 10^{3} \mathrm{kcal} / \mathrm{t}\right.$ of slag at $\left.1370^{\circ} \mathrm{C}\right)$.

In comparison with the conventional cupola process, the dissolving energy (kcal/t-loose wool) are about one eighth (1/8) for this process.

(2) Generation of waste gas in this process is much less than in the cupola process.

(3) Good product quality and high production yield can be achieved by constant control of the tapping amount and the temperature by the electric furnace tilting method.

(4) Without use of coke, the composition fluctuates less and has no inclusion of foreign matter, resulting in an improved quality.

(5) Adoption of the sealed structure type electric furnace gives high energy efficiency.

Table 1. Chemical composition of slag. (\%)

\begin{tabular}{lcc}
\hline & B. F. slag & M. slag \\
\hline $\mathrm{SiO}_{2}$ & $33 \sim 36$ & $41 \sim 42$ \\
$\mathrm{Al}_{2} \mathrm{O}_{3}$ & $13 \sim 16$ & $13 \sim 17$ \\
$\mathrm{CaO}$ & $39 \sim 41$ & $36 \sim 37$ \\
$\mathrm{MgO}$ & $3 \sim 8$ & $4 \sim 5$ \\
$\mathrm{FeO}+\mathrm{Fe}_{2} \mathrm{O}_{3}$ & 0.5 & 0.5 under \\
$\mathrm{TiO}_{2}$ & 0.8 & 1 under \\
\hline
\end{tabular}

\footnotetext{
* For further information, write to Chemical Plant Division, Plant \& Machinery Division, Nippon Steel Corporation, 2-6-3, Otemachi, Chiyoda-ku, Tokyo $100 . \quad$ (C) 1987 ISIJ
} 